\title{
Evaluating estimated glomerular filtration rates of creatinine and cystatin C for male patients with chronic spinal cord injury
}

\author{
Takuro Goto $^{1} \cdot$ Yoshihide Kawasaki $^{2} \cdot J_{\text {Jn Takemoto }}^{1} \cdot$ Yuko Abe $^{1} \cdot$ Takashige Namima $^{1}$
}

Received: 3 August 2017 / Revised: 11 November 2017 / Accepted: 13 November 2017 / Published online: 10 January 2018

(c) International Spinal Cord Society 2018

\begin{abstract}
Study design Retrospective study

Objectives To compare the accuracy of estimated serum creatinine (Cre)-based glomerular filtration rates (eGFRcre) and serum cystatin C (CysC)-based eGFR (eGFRcys) for determining renal function in patients with spinal cord injury (SCI). Setting Department of Urology, Tohoku Rosai Hospital, Japan

Methods Male patients with SCI for longer than 5 years after injury were eligible for inclusion in this study. eGFRcre and eGFRcys were calculated using the following formulas: eGFRcre $=194 \times \mathrm{Cre}^{-1.094} \times$ age $^{-0.287}$; eGFRcys $=(104 \times$ $\left.\mathrm{CysC}^{-0.1019} \times 0.996^{\mathrm{age}}\right)-8$. The eGFRcre/eGFRcys ratio between 0.8 and 1.2 was considered to be equal, and a relationship between them was investigated. Demographic data, degree of spinal cord damage, management of bladder emptying, postinjury period, and ambulatory status were evaluated.

Results A total of 115 male patients were included. eGFRcre overestimated renal function in 87 (76\%) patients with SCI compared with eGFRcys. On univariate analysis, renal function by eGFRcre was overestimated in patients with an eGFRcre of more than $60 \mathrm{ml} \mathrm{min}^{-1}$ per $1.73 \mathrm{~m}^{2}(P<0.001)$, in non-ambulatory patients $(P<0.001)$ and, in patients with complete paralysis $(P<0.001)$. On multivariate analysis, an eGFRcre of more than $60 \mathrm{ml} \mathrm{min}^{-1}$ per $1.73 \mathrm{~m}^{2}(P<0.001)$, nonambulatory status $(P<0.001)$, complete paralysis $(P=0.17)$, and age $(P<0.001)$ were independent factors for overestimated renal function by eGFRcre.

Conclusions eGFRcre overestimates renal function compared with eGFRcys. eGFRcys is beneficial, particularly in patients with an eGFRcre of more than $60 \mathrm{ml} \mathrm{min}^{-1}$ per $1.73 \mathrm{~m}^{2}$, in non-ambulatory patients, and in older patients with SCI.
\end{abstract}

\section{Introduction}

Estimated serum creatinine (Cre)-based glomerular filtration rates (eGFRcre) are commonly used to evaluate renal function [1, 2]. Cre production is dependent on muscle mass, and the concentration of Cre is influenced by renal handling and metabolism as well as by food intake [2, 3]. Patients with chronic spinal cord injury (SCI) exhibit decreased muscle mass. Therefore, Cre has been reported to

Yoshihide Kawasaki

kawasaki@uro.med.tohoku.ac.jp

1 Department of Urology, Tohoku Rosai Hospital, 4-3-21, Dainohara, Aoba-ku, Miyagi, Sendai 981-8563, Japan

2 Department of Urology, Tohoku University Graduate School of Medicine, 1-1, Seiryo-machi, Aoba-ku, Miyagi, Sendai 980-8574, Japan be an unreliable indicator of renal function in some patients with SCI [4].

Cystatin $\mathrm{C}(\mathrm{CysC})$ is a beneficial marker of glomerular filtration rate (GFR). CysC is a non-glycosylated low molecular weight protein. It is produced by all nucleated cells at a constant rate, freely filtered in the glomeruli, and reabsorbed and catabolized in the proximal tubular cells. The blood concentration of $\mathrm{CysC}$ depends almost entirely on the GFR and is not substantially affected by diet or nutritional status. CysC is independent of gender, age $(>1$ year), and muscle mass [5-7]. In SCI patients, it has been reported that $\mathrm{CysC}$ correlated better with GFR measured by ${ }^{51} \mathrm{Cr}$-ethylenediaminetetraacetic acid (EDTA) clearance or 24-h creatinine clearance than did Cre [8, 9].

The objective of this study was to compare the accuracy of eGFRcre and serum cystatin C-based eGFR (eGFRcys) for determining renal function and to detect which SCI patients should be evaluated by $\mathrm{CysC}$. 


\section{Methods}

\section{Patients}

In this retrospective study, 239 patients with SCI who had been under management of bladder emptying in our hospital were recruited from April 2011 to March 2016. Male patients with an SCI for longer than 5 years who were evaluated by both $\mathrm{Cre}$ and $\mathrm{CysC}$ on regular visits were included. Almost all SCI patients had Cre measured, and about half of the patients had CysC measured once a year. We used the blood sample on first regular visit during the study period. A total of 115 male patients were eligible for inclusion in this study.

\section{Procedure}

We reviewed the medical records of the patients. Renal function in all patients was assessed using eGFRcre and eGFRcys. Cre and CysC were measured using an enzymatic method and colloidal gold agglutination, respectively. eGFRcre and eGFRcys were calculated using the following formulas, as defined by the Clinical Practice Guidebook for Diagnosis and Treatment of Chronic Kidney Disease (CKD) 2012 in Japan: eGFRcre $=194 \times \mathrm{Cre}^{-1.094} \times$ age $^{-0.287}$; eGFRcys $=\left(104 \times\right.$ Cys $\left.^{-0.1019} \times 0.996^{\text {age }}\right)-8 \quad[10] . \quad W e$ considered eGFRcre and eGFRcys to be equal when the eGFRcre/eGFRcys ratio was between 0.8 and 1.2. When the ratio was $<0.8$, renal function was underestimated by eGFRcre, and when the ratio was $>1.2$, it was overestimated by eGFRcre. We investigated the overestimation rate by stratification of the eGFRcre ranges $(<30,30-59,60-89$, 90-119, 120-149, and 150+). We evaluated the number of patients with an eGFRcys $<60 \mathrm{ml} \mathrm{min}^{-1}$ per $1.73 \mathrm{~m}^{2}$ in each GFR category using the eGFRcre. Similarly, we evaluated the number of patients with eGFRcys $<45 \mathrm{ml} \mathrm{min}^{-1}$ per $1.73 \mathrm{~m}^{2}$ in each GFR category using the eGFRcre. GFR categories were defined by the Kidney Disease Improving Global Outcomes (KDIGO) 2012 CKD Guideline [11]. Observational data included the following: (1) demographic data (age, gender, years from injury); (2) location of spinal cord damage (cervical, thoracic, or lumbosacral); (3) paralysis status (complete or incomplete); (4) management of bladder emptying at the time of study (spontaneous micturition, selfcatheterization, or indwelling catheterization; indwelling catheterization included urethral and suprapubic catheterization); (5) ambulatory status (ambulatory status included patients who could walk, and non-ambulatory status included wheelchair users and bedridden patients).

\section{Statistical analyses}

Categorical variables were compared using the chi-square test or Fisher's exact test, and continuous variables were compared using Student's $t$-test. Clinical factors and their associated clinical outcomes were assessed by multivariate analysis with logistic regression analysis.

Data were expressed as the median (IQR) or the mean (SD). We considered a $P$-value $<0.05$ to be significant. All statistical analyses were performed with EZR (Saitama Medical Center, Jichi Medical University, Saitama, Japan) which is a graphical user interface for $\mathrm{R}$ version 3.2.2 ( $\mathrm{R}$ Foundation for Statistical Computing, Vienna, Austria) [12]. The ethical committee at Tohoku Rosai Hospital approved this study protocol.

\section{Results}

A total of 115 male patients (median age, 66 years; age range, 30-84 years; interquartile range, 58-72) were followed for a median of 23.3 years (range, 6.8-54.3 years; interquartile range, 14.2-39.1) after SCI. Among all patients (57 with cervical injury and, 58 with thoracic or lumbosacral injury), 76 (66\%) had complete paralysis at the time of study initiation. Sixteen patients had spontaneous micturition, while 50 required self-catheterization, and 49 required indwelling catheterization at that time. Mean (SD) Cre and CysC were 0.58 (0.29) $\mathrm{mg} \mathrm{dl}^{-1}$ and 1.07 (0.44) $\mathrm{mg} \mathrm{l}^{-1}$, respectively, eGFRcre and eGFRcys were 130.6 (54.7) and 79.2 (24.4) $\mathrm{ml} \mathrm{min}^{-1}$ per $1.73 \mathrm{~m}^{2}$, respectively. Based on eGFRcre/eGFRcys ratios, eGFRcre overestimated renal function in $87(76 \%)$ patients with chronic SCI. eGFRcre was almost equivalent (90\%) to eGFRcys in ambulatory patients with chronic SCI. There were no patients whose renal function was underestimated by the eGFRcre (Table 1, Fig. 1).

In patients with chronic SCI, a higher eGFRcre increased the overestimation rate of eGFR. However, only $22 \%$ of patients ( 2 of 9) with an eGFRcre $<60 \mathrm{ml} \mathrm{min}^{-1}$ per $1.73 \mathrm{~m}^{2}$ (GFR category G3a-G5) were overestimated (Fig. 2). In addition, 78\% (7 of 9) patients in GFRcre category G3a-G5 had a result $<60 \mathrm{ml} \mathrm{min}^{-1}$ per $1.73 \mathrm{~m}^{2}$ by eGFRcys (Fig. 3). All four patients with an eGFRcre $<45 \mathrm{ml} \mathrm{min}^{-1}$ per $1.73 \mathrm{~m}^{2}$ (GFR category G3b-G5) also had a result $<45 \mathrm{ml} \mathrm{min}^{-1}$ per $1.73 \mathrm{~m}^{2}$ by eGFRcys (Fig. 4). On the other hand, there were 30 patients with an eGFRcre of $>150 \mathrm{ml} \mathrm{min}^{-1}$ per $1.73 \mathrm{~m}^{2}$, and 28 of $30(93 \%)$ patients had an eGFRcys $>60 \mathrm{ml} \mathrm{min}^{-1}$ per $1.73 \mathrm{~m}^{2}$. When we used eGFRcre $60 \mathrm{ml} \mathrm{min}^{-1}$ per $1.73 \mathrm{~m}^{2}$ as a cutoff value of renal deterioration which defined by eGFRcys $<60 \mathrm{ml} \mathrm{min}^{-}$ ${ }^{1}$ per $1.73 \mathrm{~m}^{2}$, the sensitivity was $78 \%$ and the specificity was $82 \%$.

On univariate analysis, renal function by eGFRcre was significantly overestimated when compared with eGFRcys in patients with an eGFRcre of $>60 \mathrm{ml} \mathrm{min}^{-1}$ per $1.73 \mathrm{~m}^{2}$ $(P<0.001)$, in non-ambulatory patients $(P<0.001)$ and in 
Table 1 Characteristics of patients with spinal cord injuries (median (IQR) or mean (SD)) and factors associated with eGFRcys/eGFRcre ratio difference

\begin{tabular}{|c|c|c|c|c|}
\hline \multirow[b]{2}{*}{ eGFRcre/eGFRcys ratio } & \multicolumn{3}{|l|}{ Total } & \multirow[t]{2}{*}{$P$-value } \\
\hline & & $0.8-1.2$ & $>1.2$ & \\
\hline No. of patients & 115 & 28 & 87 & \\
\hline Median age (IQR) & $66(58-72)$ & $61.5(52-73.3)$ & $67(60.5-72)$ & 0.108 \\
\hline Median years since injury (IQR) & $23.3(14.2-39.1)$ & $18.5(13.3-27.0)$ & $26.6(14.9-40.8)$ & 0.029 \\
\hline Cre $\left(\mathrm{mg} \mathrm{dl}^{-1}\right)$ & $0.58 \pm 0.29$ & $0.81 \pm 0.34$ & $0.50 \pm 0.22$ & $<0.001$ \\
\hline eGFRcre $\left(\mathrm{ml} \mathrm{min}^{-1}\right.$ per $\left.1.73 \mathrm{~m}^{2}\right)$ & $130.6 \pm 54.9$ & $87.8 \pm 30.3$ & $144.4 \pm 54.0$ & $<0.001$ \\
\hline CysC $\left(\mathrm{mg} \mathrm{l}^{-1}\right)$ & $1.07 \pm 0.44$ & $1.05 \pm 0.48$ & $1.08 \pm 0.43$ & 0.831 \\
\hline eGFRcys $\left(\mathrm{ml} \mathrm{min}^{-1}\right.$ per $\left.1.73 \mathrm{~m}^{2}\right)$ & $79.2 \pm 24.4$ & $84.7 \pm 28.0$ & $77.5 \pm 23.0$ & 0.171 \\
\hline No. of patients with eGFRcre $<60$ & 9 & $7(78 \%)$ & 2 & $<0.001$ \\
\hline No. of patients with eGFRcys $<60$ & 26 & $5(19 \%)$ & 21 & 0.608 \\
\hline Ambulation (AIS) & & & & $<0.001$ \\
\hline Non-ambulatory & 105 & $19(18 \%)$ & 86 & \\
\hline Ambulatory (non A-B) & 10 & $9(90 \%)$ & 1 & \\
\hline Paralysis (AIS) & & & & $<0.001$ \\
\hline Complete SCI (A) & 76 & $10(13 \%)$ & 66 & \\
\hline Incomplete SCI (B-D) & 39 & $18(46 \%)$ & 21 & \\
\hline Bladder management & & & & 0.052 \\
\hline Indwelling catheters & 64 & $11(17 \%)$ & 53 & \\
\hline Spontaneous voiding /CIC & 51 & $17(33 \%)$ & 34 & \\
\hline Level of injury & & & & 0.278 \\
\hline Cervical & 57 & $11(19 \%)$ & 46 & \\
\hline Thoracic/lumbosacral & 58 & $17(29 \%)$ & 41 & \\
\hline
\end{tabular}

IQR interquartile range, AIS American Spinal Injury Association Impairment Scale, $e G F R$ estimated serum creatinine glomerular filtration rates, Cre creatinine, CysC cystatin C, SCI spinal cord injury, CIC clean intermittent catheterization

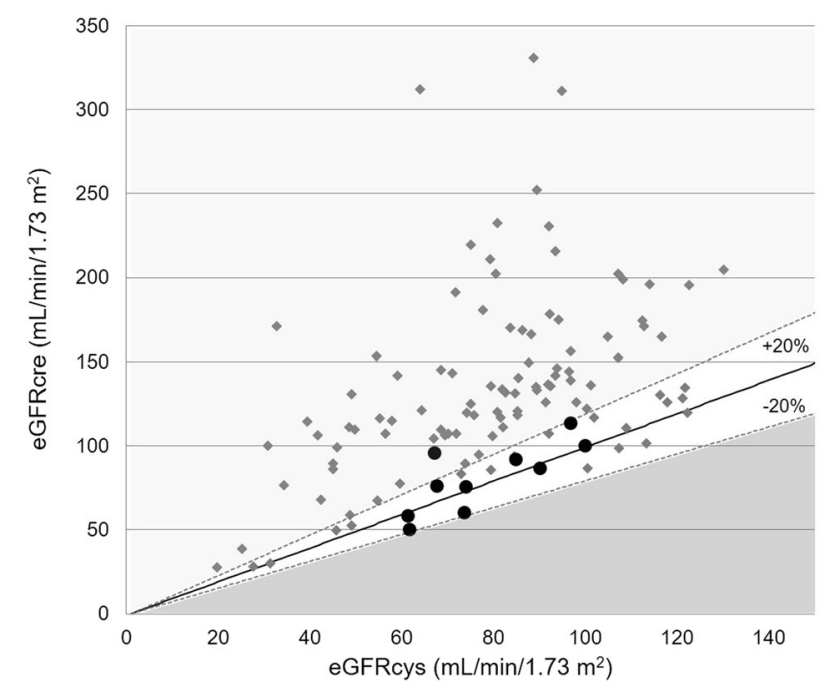

Fig. 1 Relationship between eGFRcre and eGFRcys. Points between dotted lines are equivalent and points above an upper dotted line are overestimated by eGFRcre when compared with eGFRcys. $\bullet$ ambulatory patients $(n=10) ; \bullet$ non-ambulatory patients $(n=105)$

patients with complete paralysis $(P<0.001)$. Number of years after spinal cord injury was also a factor in overestimation of renal function by eGFRcre $(P=0.029)$.

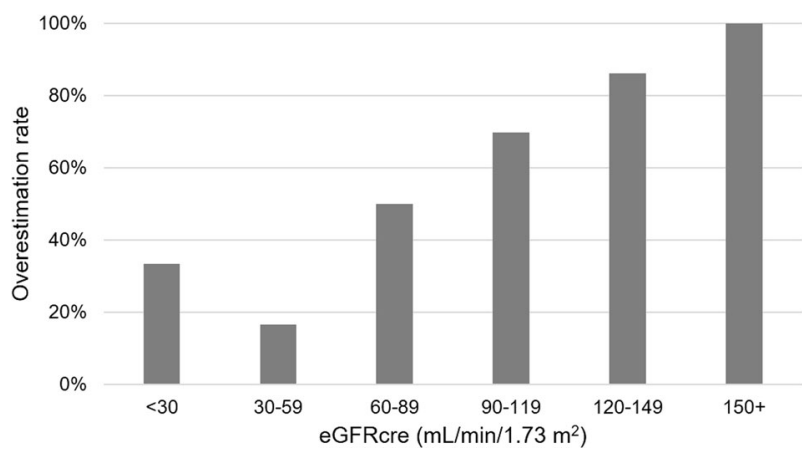

Fig. 2 Percentage of patients with renal function overestimated by eGFRcre when compared with eGFRcys according to the level of eGFRcre

Management of bladder emptying and cervical injury or injury at another site were not independent factors that impacted overestimation of eGFR $(P=0.052, P=0.301$, respectively) (Table 1). On multivariate analysis, renal function by eGFRcre was significantly overestimated when compared with eGFRcys in patients with an eGFRcre of $>60 \mathrm{ml} \mathrm{min}^{-1}$ per $1.73 \mathrm{~m}^{2}(P<0.001)$, in non-ambulatory patients $(P=0.002)$, in patients with complete paralysis 


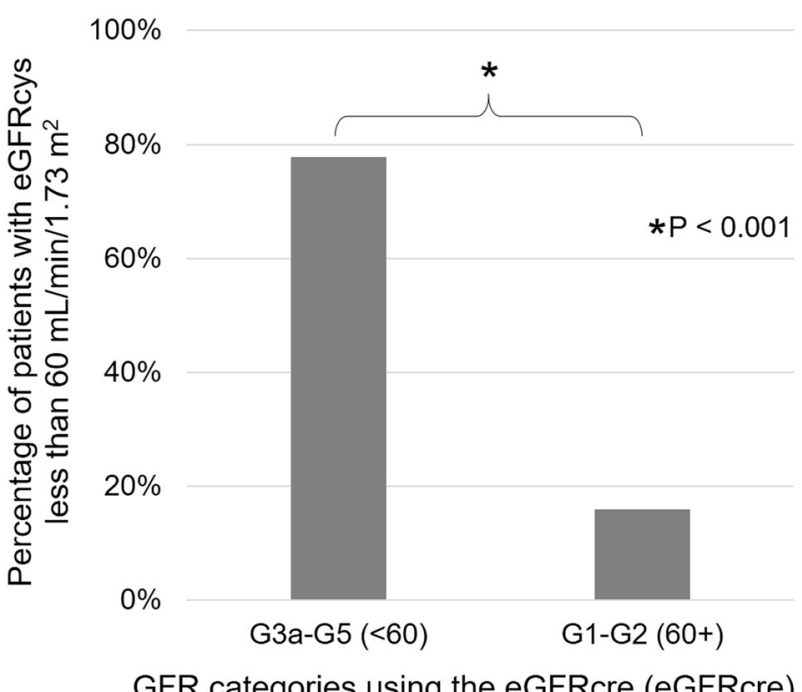

Fig. 3 Percentage of patients with eGFRcys $<60 \mathrm{ml} \mathrm{min}^{-1}$ per $1.73 \mathrm{~m}^{2}$. Categories G3a-G5 had a result $<60 \mathrm{ml} \mathrm{min}^{-1}$ per $1.73 \mathrm{~m}^{2}$ by eGFRcre. Categories G1-G2 had a result $>60$ and $60 \mathrm{ml} \mathrm{min}^{-1}$ per $1.73 \mathrm{~m}^{2}$ by eGFRcre. A significant difference was found between groups $\left({ }^{*} P<0.001\right)$

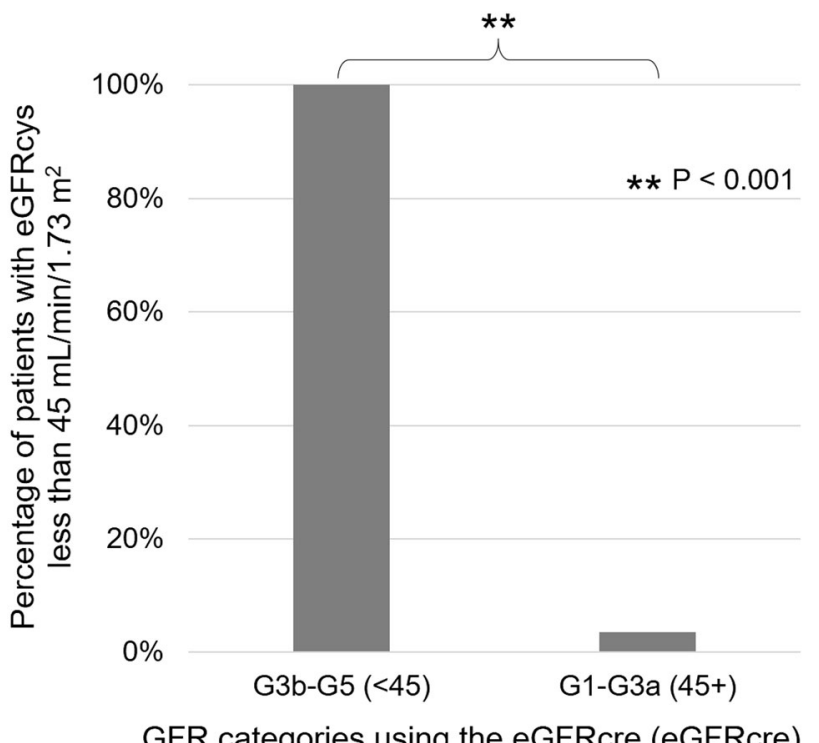

Fig. 4 Rate of patients with eGFRcys $<45 \mathrm{ml} \mathrm{min}^{-1}$ per $1.73 \mathrm{~m}^{2}$. Categories G3b-G5 had a result $<45 \mathrm{ml} \mathrm{min}^{-1}$ per $1.73 \mathrm{~m}^{2}$ by eGFRcre. Categories G1-G3a had a result $>45$ and $45 \mathrm{ml} \mathrm{min}^{-1}$ per $1.73 \mathrm{~m}^{2}$ by eGFRcre. A significant difference was found between groups (** $P<0.001$ )

$(P=0.017)$ and in older patients $(P<0.001)$ (Table 2$)$. When stratified by SCI level, eGFRcre in patients with cervical injury was equal to that of those with thoracic injury but was overestimated when compared with those with lumbosacral injury (Table 3).
Table 2 Factors associated with overestimation of renal function using eGFRcre by multivariate analysis

\begin{tabular}{llll}
\hline & Odds ratio & $95 \%$ CI & $P$-value \\
\hline $\begin{array}{l}\text { eGFRcre }>60 \mathrm{ml} \mathrm{min}^{-1} \\
\text { per } 1.73 \mathrm{~m}^{2}\end{array}$ & 83.3 & $8.74-794$ & $<0.001$ \\
Non-ambulatory & 45.5 & $4.05-511$ & 0.002 \\
Age & 1.11 & $1.04-1.16$ & $<0.001$ \\
Complete paralysis & 4.79 & $1.32-17.4$ & 0.017 \\
\hline
\end{tabular}

CI confidence interval

\section{Discussion}

In this study, we estimated renal function in patients with SCI investigating with the eGFRcre/eGFRcys ratio. Our results indicated that we might have overestimated many of those patients' renal function when using the Cre method. Erlandsen et al. [13] reported that eGFR using the Cre method matched only $50 \%$ of SCI patients compared with GFR measured by ${ }^{51} \mathrm{Cr}$ - EDTA clearance. They considered a ratio of eGFRcre to measured GFR between 0.7 and 1.3 to be equal, and this result was similar to our study. Evaluating renal function precisely leads to early detection of CKD, which is defined as a GFR less than $60 \mathrm{~min}^{-1}$ per $1.73 \mathrm{~m}^{2}$. CKD is associated with an increased risk of adverse outcomes including cardiovascular events, development of end-stage renal disease, and death [14].

It has been reported that patients with SCI may be more likely to develop CKD because they have risk factors for CKD such as high-pressure voiding, vesicoureteral reflux, urinary tract infection, and renal calculi [4]. Moreover, CKD has been shown to be a strong predictor of mortality in adults with SCI [15]. Therefore, it is important to detect early-stage CKD in these patients.

To our knowledge, renal function is evaluated by serum Cre in general practice because of its convenience and low cost. However, previous studies have found that serum Cre is not able to detect the early deterioration of renal function $[4,8]$. CysC is a sensitive marker for detecting a reduced GFR and improves the detection of patients with CKD at an earlier stage. It has been established that $\mathrm{CysC}$ is superior to serum Cre for eGFR, but CysC is not the gold standard. Reference methods include inulin clearance and isotopic methods. Serum CysC-based equations have been proposed and validated, such as the Chronic Kidney Disease

Table 3 Odds ratio stratified by level of injury

\begin{tabular}{lllllll}
\hline Level of injury & No. & $0.8-1.2$ & $>1.2$ & $\begin{array}{l}\text { Odds } \\
\text { ratio }\end{array}$ & $95 \%$ CI & $P$-value \\
\hline Cervical & 57 & 11 & 46 & - & - & - \\
Thoracic & 44 & 10 & 34 & 0.81 & $0.28-2.41$ & 0.81 \\
Lumbosacral & 14 & 7 & 7 & 0.25 & $0.059-1.00$ & 0.035 \\
\hline
\end{tabular}


Epidemiology Collaboration (CKD-EPI) creatinine/cystatin $\mathrm{C}$ combined equation, and the CKD-EPI cystatin $\mathrm{C}$ equation [16]. In general population cohorts, CysC is a stronger predictor for cardiovascular disease and risk of death than Cre [17, 18]. Mingat et al. [19] reported that an equation using cystatin $\mathrm{C}$ was the most precise method of renal function evaluation in patients with various causes of neurogenic bladder including multiple sclerosis, spinal cord injury, spina bifida, etc. Serum CysC is also a better index of renal function than Cre in patients with SCI [8, 9, 13]. Therefore, we compared Cre with $\mathrm{CysC}$, considering $\mathrm{CysC}$ as a reference.

However, there is a disadvantage associated with $\mathrm{CysC}$ in the follow-up of patients with established renal disease such as IgA nephropathy, diabetic nephropathy, and glomerulonephritis because the rise in $\mathrm{CysC}$ is blunted compared with Cre at a lower GFR [20, 21]. Thus, Cre is still the better assay for following sequential changes in an individual with confirmed renal disease and this would be the same for patients with SCI.

It is unclear in which SCI patients CysC measurement should be used, i.e., presence or absence of cervical injury, complete or incomplete paralysis, ambulatory or not, age, time from injury, etc. In the present study, we identified patients whose renal function should be evaluated by CysC. According to our results on univariate analysis, CysC was effective for patients with an eGFRcre of more than $60 \mathrm{~min}^{-1}$ per $1.73 \mathrm{~m}^{2}$, non-ambulatory status, and complete paralysis. Only when compared with lumbosacral injury patients, CysC was effective for cervical injury patients. The main reason is the dramatic loss of muscle mass below the level of the injury lesion after SCI. Leg and trunk lean masses were significantly lower than arm lean mass [22]. We should use CysC to detect early-stage CKD for patients with such muscle loss. On the other hand, eGFRcre was equivalent to eGFRcys in $90 \%$ of ambulatory patients. Mingat et al. evaluated renal function of patients with neurogenic bladder and investigated mobility status, i.e., ambulatory or wheelchair. They reported that the CysC equation was the most precise method. However, when using the Cre equation, the bias was small in ambulatory patients. This result supports our study [18].

On multivariate analysis, age was also one of the factors related to overestimation of renal function using eGFRcre. Some reports describe that serum Cre decreases over time in SCI patients, despite an increasing risk of developing renal insufficiency [23]. Extensive loss of muscle mass with increasing age in SCI patients is thought to be the biggest reason for the decrease in serum Cre.

As mentioned, a higher eGFRcre increases the possibility of overestimation of renal function. On the other hand, our data show that the discrepancy between eGFRcre and eGFRcys could be smaller in SCI patients with a lower eGFRcre. About $80 \%$ of patients with an eGFRcre $<60 \mathrm{~min}^{-1}$ per $1.73 \mathrm{~m}^{2}$ also had an eGFRcys $<60 \mathrm{~min}^{-1}$ per $1.73 \mathrm{~m}^{2}$. We suggest that Cre could be used to evaluate renal function in SCI patients with an eGFRcre $<60 \mathrm{~min}^{-1}$ per $1.73 \mathrm{~m}^{2}$. CysC would be beneficial for the detection of early-stage CKD, especially for patients with an eGFRcre of $>60 \mathrm{~min}^{-1}$ per $1.73 \mathrm{~m}^{2}$. Among the patients who seem to be normal when evaluated by Cre, patients with CKD accounted for $20 \%$. Therefore, they need to be evaluated by CysC. More than $90 \%$ of patients with an eGFRcre of $>150 \mathrm{~min}^{-1}$ per $1.73 \mathrm{~m}^{2}$ had an eGFRcys $>60 \mathrm{~min}^{-1}$ per $1.73 \mathrm{~m}^{2}$. Those patients might have normal renal function; however, we should pay attention to the fact that all of them were overestimated.

Zhang et al. [24] has reported that indwelling catheterization was a predictor of upper urinary tract deterioration in SCI patients. However, there was no difference in renal function based on the type of bladder emptying management in our study. Renal function of our patients had been maintained. Therefore, Cre did not overestimate renal function when compared with eGFRcys in patients with an indwelling catheter.

Limitations of this study included its observational and retrospective nature. The patients were all men. These results were determined based on a sample of 115 male veterans at a single hospital; therefore, its accuracy and generalizability are uncertain. Another limitation of our study is the lack of a comparison with gold standard methods using inulin or a radioactive marked tracer. This study was retrospective and based on data collected from clinical records. The inulin or radioactive marker methods are not used in clinical practice and they are not covered by medical insurance in Japan.

A recent study has shown that calculation of the eGFR with a combination of Cre and CysC more accurately reflects measured GFR than either marker alone [15]. Moreover, in SCI patients, newer SCI equations that lead to more accurate estimation of GFR have been developed [25, 26]. However, these have not been used in general practice. Longitudinal research studies are needed to examine the estimation of renal function of SCI patients to more accurately predict intermediate and long-term clinical outcomes.

\section{Conclusions}

In our study, we revealed that renal function evaluated by eGFRcre is often overestimated when compared with eGFRcys, and eGFRcys should be recommended for SCI patients, especially in patients with an eGFRcre of $>60 \mathrm{~min}^{-1}$ per $1.73 \mathrm{~m}^{2}$, patients with non-ambulatory status, patients with complete paralysis, and older patients. Cre is not recommended for, and $\mathrm{CysC}$ is useful in, the detection 
of early-stage CKD for SCI patients with an eGFRcre of $>60 \mathrm{~min}^{-1}$ per $1.73 \mathrm{~m}^{2}$. For patients with an eGFRcre $<60 \mathrm{~min}^{-1}$ per $1.73 \mathrm{~m}^{2}$, we can continue to use Cre, which may still be useful to follow high-grade CKD in SCI patients.

Acknowledgements We are thankful that we had the opportunity to report a part of this study at the International Continence Society Annual Meeting 2016. The abstract has been published: https://www. ics.org/Abstracts/Publish/326/000188.pdf.

\section{Compliance with ethical standards}

Conflict of interest The authors declare that they have no conflict of interest.

\section{References}

1. Thomas L, Huber AR. Renal function-estimation of glomerular filtration rate. Clin Chem Lab Med. 2006;44:1295-302.

2. Perrone RD, Madias NE, Levey AS. Serum creatinine as an index of renal function: new insights into old concepts. Clin Chem. 1992;38:1933-53.

3. Blijenberg BG, Brouwer HJ, Kuller TJ, Leeneman R, van Leeuwen CJ. Improvements in creatinine methodology: a critical assessment. Eur J Clin Chem Clin Biochem. 1994;32:529-37.

4. MacDiarmid SA, McIntyre WJ, Anthony A, Bailey RR, Turner JG, Arnold EP. Monitoring of renal function in patients with spinal cord injury. BJU Int. 2000;85:1014-8.

5. Randers E, Erlandsen EJ. Serum cystatin $\mathrm{C}$ as an endogenous marker of the renal function-a review. Clin Chem Lab Med. 1999;37:389-95.

6. Ferguson TW, Komenda P, Tangri N. Cystatin C as a biomarker for estimating glomerular filtration rate. Curr Opin Nephrol Hypertens. 2015;24:295-300.

7. Filler G, Bökenkamp A, Hofmann W, Le Bricon T, Martínez-Brú C, Grubb A. Cystatin C as a marker of GFR-history, indications, and future research. Clin Biochem. 2005;38:1-8.

8. Thomassen SA, Johannesen IL, Erlandsen EJ, Abrahamsen J, Randers E. Serum cystatin C as a marker of the renal function in patients with spinal cord injury. Spinal Cord. 2002;40:524-8.

9. Jenkins MA, Brown DJ, Ierino FL, Ratnaike SI. Cystatin C for estimation of glomerular filtration rate in patients with spinal cord injury. Ann Clin Biochem. 2003;40:364-8.

10. Horio M, Imai E, Yasuda Y, Watanabe T, Matsuo S. Performance of GFR equations in Japanese subjects. Clin Exp Nephrol. 2013;17:352-8.

11. Kidney Disease. Improving Global Outcomes (KDIGO) CKD Work Group. KDIGO 2012 Clinical Practice Guideline for the
Evaluation and Management of Chronic Kidney Disease. Kidney Int Suppl. 2013;3:1-150.

12. Kanda Y. Investigation of the freely available easy-to-use software 'EZR' for medical statistics. Bone Marrow Transplant. 2013;48:452-8.

13. Erlandsen EJ, Hansen RM, Randers E, Petersen LE, Abrahamsen J, Johannesen IL. Estimating the glomerular filtration rate using serum cystatin $\mathrm{C}$ levels in patients with spinal cord injuries. Spinal Cord. 2012;50:778-83.

14. Go AS, Chertow GM, Fan D, McCulloch CE, Hsu CY. Chronic kidney disease and the risks of death, cardiovascular events, and hospitalization. N Engl J Med. 2004;351:1296-305.

15. Greenwell MW, Mangold TM, Tolley EA, Wall BM. Kidney disease as a predictor of mortality in chronic spinal cord injury. Am J Kidney Dis. 2007;49:383-93.

16. Inker LA, Schmid CH, Tighiouart H, Eckfeldt JH, Feldman HI, Greene $\mathrm{T}$, et al. Estimating glomerular filtration rate from serum creatinine and cystatin C. N Engl J Med. 2012;367:20-9.

17. Shlipak MG, Sarnak MJ, Katz R, Fried LF, Seliger SL, Newman $\mathrm{AB}$, et al. Cystatin $\mathrm{C}$ and the risk of death and cardiovascular events among elderly persons. N Engl J Med. 2005;352: 2049-60.

18. Shlipak MG, Matsushita K, Ärnlöv J, Inker LA, Katz R, Polkinghorne $\mathrm{KR}$, et al. Cystatin $\mathrm{C}$ versus creatinine in determining risk based on kidney function. N Engl J Med. 2013;369:932-43.

19. Mingat N, Villar E, Allard J, Castel-Lacanal E, Guillotreau J, Malavaud B, et al. Prospective study of methods of renal function evaluation in patients with neurogenic bladder dysfunction. Urology. 2013;82:1032-7.

20. Yashiro M, Kamata T, Segawa H, Kadoya Y, Murakami T, Muso E. Comparisons of cystatin $\mathrm{C}$ with creatinine for evaluation of renal function in chronic kidney disease. Clin Exp Nephrol. 2009;13:598-604.

21. Keevil BG, Kilpatrick ES, Nichols SP, Maylor PW. Biological variation of cystatin $\mathrm{C}$ : implications for the assessment of glomerular filtration rate. Clin Chem. 1998;44:1535-9.

22. Spungen AM, Wang J, Pierson RN Jr., Bauman WA. Soft tissue body composition differences in monozygotic twins discordant for spinal cord injury. J Appl Physiol. 2000;88:1310-5.

23. Elmelund M, Oturai OS, Biering-Sorensen F. 50 years follow-up on plasma creatinine levels after spinal cord injury. Spinal Cord. 2014;52:368-72.

24. Zhang Z, Liao L. Risk factors predicting upper urinary tract deterioration in patients with spinal cord injury: a prospective study. Spinal Cord. 2014;52:468-71.

25. Chikkalingaiah KB, Grant ND, Mangold TM, Cooke CR, Wall BM. Performance of simplified modification of diet in renal disease and Cockcroft-Gault equations in patients with chronic spinal cord injury and chronic kidney disease. Am J Med Sci. 2010;339:108-16.

26. Lee JP, Dang AT. Evaluation of methods to estimate glomerular filtration rate versus actual drug clearance in patients with chronic spinal cord injury. Spinal Cord. 2011;49:1158-63. 